\title{
Primary Leiomyosarcoma of the Prostate Invading the Rectum and Bladder
}

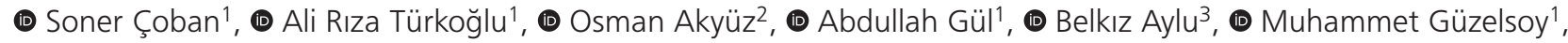 \\ (D) Turgut Kaçan ${ }^{4}$, (D) Hülya Haksever ${ }^{5}$, (D) Ünal Kurtoğlú ${ }^{6}$ \\ ${ }^{1}$ University of Health Sciences Turkey, Bursa Yüksek Ihtisas Training and Research Hospital, Clinic of Urology, Bursa, Turkey \\ ${ }^{2}$ Biruni University Medicine Hospital, Clinic of Urology, Istanbul, Turkey \\ ${ }^{3}$ University of Health Sciences Turkey, Bursa Yüksek Ihtisas Training and Research Hospital, Clinic of General Surgery, Bursa, Turkey \\ ${ }^{4}$ University of Health Sciences Turkey, Bursa Yüksek Ihtisas Training and Research Hospital, Clinic of Medical Oncology, Bursa, Turkey \\ 5 University of Health Sciences Turkey, Bursa Yüksek Ihtisas Training and Research Hospital, Clinic of Pathology, Bursa, Turkey \\ ${ }^{6}$ University of Health Sciences Turkey, Bursa Yüksek Ihtisas Training and Research Hospital, Clinic of Radiology, Bursa, Turkey
}

\begin{abstract}
Prostate sarcomas originate from the mesenchymal tissues including smooth muscle, fibromuscular stroma, paraganglia, nerves, and blood vessels. They account for less than $0.1 \%$ of all prostate tumors and often present with obstructive symptoms. Patients with leiomyosarcoma of the prostate commonly have poor prognosis and their life expectancy varies between $0 \%$ and $60 \%$ depending on the stage of the disease at the initial diagnosis. Histopathological examination is essential for definitive diagnosis, and can be performed at an early stage using guided transrectal prostate biopsy. Since prostate specific antigen levels are generally normal, digital rectal examinations are extremely important. We report on a 50-year-old man who was diagnosed with leiomyosarcoma based on the histopathology of his transurethral prostatectomy specimen.
\end{abstract}

Keywords: Digital rectal examination, invasion, leiomyosarcoma, prostate cancer

\section{Introduction}

Sarcomas of prostate originate from the prostatic stroma, and are extremely rare. They are responsible for less than $0.1 \%$ of all primary prostate malignancies $(1,2)$. Among these, leiomyosarcoma is the most common, comprising 38\%-52\% of sarcomas, and is highly aggressive $(3,4)$. Herein, we present a patient diagnosed with prostate leiomyosarcoma after transurethral prostatectomy (TUR-P).

\section{Case Presentation}

A 50-year-old man admitted to an external clinic with lower urinary tract symptoms (LUTS) was referred to us after he underwent a TUR-P and was diagnosed with leiomyosarcoma based on the histopathology of his specimen. On preoperative digital rectal examination (DRE), the right lobe of the prostate was abnormal and fixed. Prostate specific antigen (PSA) level was $0.63 \mathrm{ng} / \mathrm{mL}$. All laboratory tests including urine analysis, serum creatinine, glucose, complete blood count etc were normal. His F18 fluorodeoxyglucose positron emission tomography/ computed tomography (PET/CT) demonstrated a mass of 6 $\mathrm{cm} \times 4.5 \mathrm{~cm}$ with an irregular size, covering the majority of the prostate gland. Maximal standardized uptake value of this lesion was 51.5 (Figure 1A). Magnetic resonance imaging (MRI) showed a mass lesion of $7 \mathrm{~cm} \times 5 \mathrm{~cm}$. Pressure effect was observed in the rectum and the bladder base. Bilateral parailiac lymph nodes with an index of about $10 \mathrm{~mm}$ were observed (Figure 1B) without any signs of distant metastasis.

Thereafter, radical cystoprostatectomy and Miles operation were performed. The patient was discharged 12 days postoperatively. In the macroscopic examination of the radical cystoprostatectomy specimen involving the adjacent rectum, the prostate showed an ulcerated appearance invading the bladder. Diameter of this lesion was $6.7 \mathrm{~cm} \times 4.5 \mathrm{~cm}$. Microscopic examination revealed nuclear pleomorphism and spindle shaped hyperchromatic nuclei. Tumor cells invaded into the bladder (Figure 2A), seminal vesicles (Figure 2B), and deep muscular layer of the colon (Figure $3 A)$. Numerous typical and atypical mitotic figures were observed among the tumor cells (Figure 3B). Immunohistochemical examination of the tumor revealed positive staining with

Cite this article as: Çoban S, Türkoğlu AR, Akyüz O, Gül A, Aylu B, Güzelsoy M, Kaçan T, Haksever H, Kurtoğlu Ü. Primary Leiomyosarcoma of the Prostate Invading the Rectum and Bladder. Bull Urooncol 2020;19(4):215-217

Address for Correspondence: Soner Çoban, University of Health Sciences Turkey, Bursa Yüksek Ihtisas Training and Research Hospital, Clinic of Urology, Bursa, Turkey E-mail: drsonercoban75@gmail.com ORCID-ID: orcid.org/0000-0002-4687-8754 20 Received: 12.07.2019 Accepted: 15.10.2019 
smooth muscle markers such as smooth muscle actin, heartin, caldesmon, and desmin (Figure 4). C-kit and Dog-1 staining
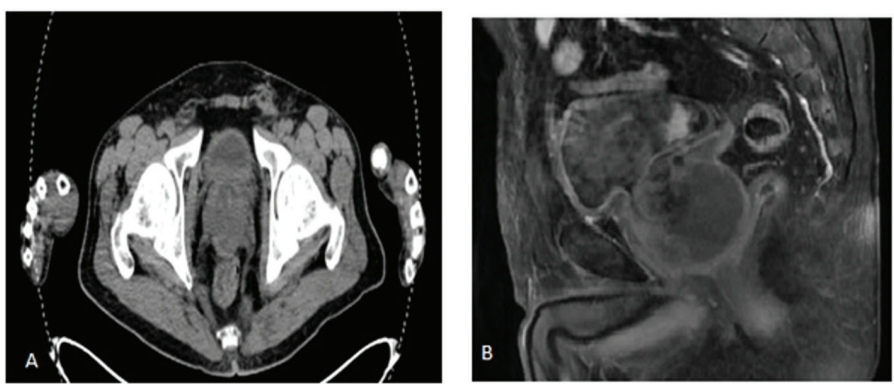

Figure 1. MR and PET/CT imaging findings of prostate leiomyosarcoma. A: PET/ CT heterogenous hypodense mass showed hypermetabolic (SUVmax: 51.5) FDG uptake at this level of malignancy. B: Prostatic MRI depicts local invasion of the bladder and rectum in contrast-enhanced T1-weighted images in prostate

MRI: Magnetic resonance imaging, PET/CT: Positron emission tomography/ computed tomography, FDG: Fludeoxyglucose, SUV: Standardized uptake value
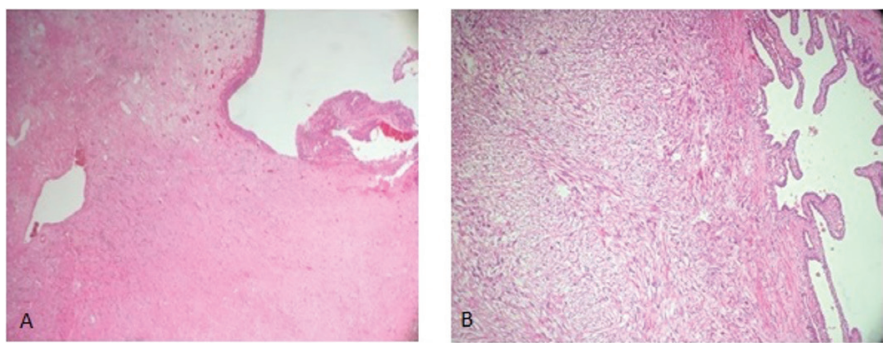

Figure 2. A: Histopathological presentation of prostate leiomyosarcoma, Invasion of the tumor into the bladder. B: Histopathological presentation of prostate leiomyosarcoma, $(4 \mathrm{x}, \mathrm{H} \& \mathrm{E})$ Seminal vesicle invation
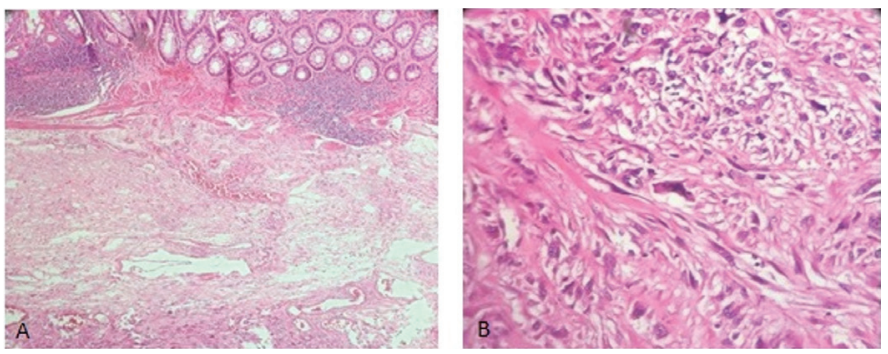

Figure 3. A: Histopathological presentation of the prostate leiomyosarcoma, the area where the tumor is infiltrated into the colon. B: Histopathological presentation of prostate leiomyosarcoma (40x, H \& E) tumor cells showing mitosis and pleomorphism

were negative. Tumor cells were not observed in the pelvic lymph nodes.

\section{Discussion}

Primary sarcomas of the prostate are extremely rare. The most common among these is leiomyosarcoma originating from the smooth muscles of the prostate. It has an aggressive clinical course (4). Presenting complaints include perineal and pelvic pain, frequent urination, hematuria, constipation, and obstructive symptoms. Serum PSA levels are typically normal due to their non-epithelial origin, making it highly difficult to

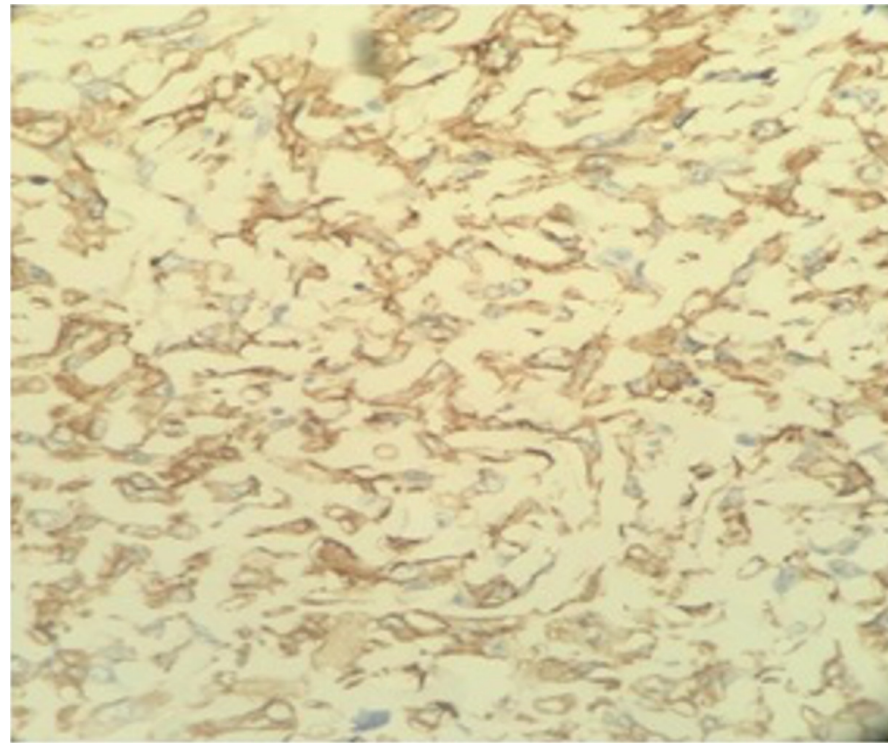

Figure 4. Histopathological presentation of prostate leiomyosarcoma, (40x) Desmin (immunohistochemistry) and tumor cells

differentiate these from benign prostatic diseases. The final diagnosis is usually accomplished via transrectal ultrasonography guided needle prostate biopsy, TUR-P, and less frequently by open surgery $(4,5)$. In this case, the diagnosis was accomplished via TUR-P. The largest diameter of the tumor was $7 \mathrm{~cm}$, it was macroscopically infiltrative, and its size was compatible with that in the literature $(3-21 \mathrm{~cm})(6)$.

Leiomyosarcoma of prostate was described by Gaudin et al. (7) in 1998. World Health Organization classifies this tumor as a distinct spindle cell neoplasm (8). Recently, "Stromal tumors of uncertain malignant potential (STUMP)" was used to define the clinical course and histological features of these tumors. Four different types of STUMP were described based on their histology. Stromal sarcoma may occur as a de novo primary or coexist with pre-existing or synchronous STUMP, indicating that the latter may potentially convert into stromal sarcoma.

Differential diagnoses of prostatic stromal sarcoma include prostate adenocarcinoma, benign prostatic hyperplasia, and prostate abscess; however, imaging features are variable.

Such tumors can invade adjacent structures such as the bladder and rectum, as in our patient. Therefore, a combination of radical cystoprostatectomy, abdomino-perineal resection, and Miles operation was performed. Routine pelvic lymphadenectomy is usually not recommended unless pathological lymph nodes are observed on radiological examination (9). We performed pelvic lymphadenectomy due to the suspected $1 \mathrm{~cm}$ large lymph nodes on MRI.

Although, there are no standardized imaging protocols to detect metastasis for prostatic leiomyosarcoma, F18 PET/CT or conventional $C T$ and MRI have been widely used $(3,4,9,10,11)$. Moreover, F18 PET/CT provides additional benefits in the diagnosis, staging, and follow-up of sarcomas $(10,11)$. We performed both F18 PET/CT and MRI for our patient.

The most important tool for early diagnosis is DRE that can detect the size of the prostate, stiffness, and the involved mass. 
However, patients may sometimes reject DRE. This report also highlighted the need for DRE to be a part of the routine physical examination, even in patients with normal PSA levels.

The prognosis of leiomyosarcoma of the prostate is poor, and it may show wide regional and distant metastasis to the lungs, liver, and bones via lymphatics and blood vessels. Approximately $25 \%$ of patients present with distant metastasis (12). About $50 \%-75 \%$ of patients with leiomyosarcoma die within 2-5 years (13). Therefore, these patients must be evaluated at centers with significant experience. The treatment should be guided by the stage of the disease. In the absence of metastasis, the most preferred treatment is radical surgery; however, total excision may not be possible in the majority of patients. Achieving negative surgical margins is rather difficult due to the invasion into the adjacent structures (4). In our patient, invasion into the right and left seminal vesicles, rectum, and bladder was observed. Additionally, the tumor had invaded the right and left posterior abdominal wall. Based on the histopathological findings, the uro-oncology council decided to prescribe chemotherapy and radiotherapy for the patient, and he is currently receiving his treatment.

\section{Conclusion}

Leiomyosarcoma of the prostate is a rare disease with a poor prognosis. Patients commonly present with LUTS, and a DRE usually reveals an abnormal prostate. Therefore, the significance of DRE should never be underestimated, even in patients with normal PSA levels.

\section{Acknowledgements}

Publication: The results of the study were not published in full or in part in form of abstracts.

Contribution: There is not any contributors who may not be listed as authors.

Conflict of Interest: No conflict of interest was declared by the authors.

Financial Disclosure: The authors declared that this study received no financial support.

\section{Ethics}

Informed Consent: Patient consent form was not obtained.

Peer-review: Externally peer-reviewed.

\section{Authorship Contributions}

Surgical and Medical Practices: S.Ç. A.R.T., B.A., Concept: S.Ç., O.A., Design: S.Ç., A.G., B.A., Data Collection or Processing: S.Ç., T.K., Analysis or Interpretation: S.Ç., O.A., Ü.K., Literature Search: S.Ç., A.R.T., M.G., Writing: S.Ç., A.G., H.H., Ü.K.

\section{References}

1. Paner GP, Aron M, Hansel DE, et al. Non-epithelial neoplasms of the prostate. Histopathology 2012;60:166-186.

2. Tetu B, Srigley JR, Bostwick DG. Soft Tissue Tumors. In: Bostwick DG, Ed. Pathology of the Prostate. New York: Churchill-Livingstone; 1990. p. 117-135.

3. Agarwal NK, Dorairanjan LN, Kumar S, et al. Primary prostatic leiomyosarcoma in an adult. Indian J Urol 2006;22:66-67.

4. Sexton WJ, Lance RE, Reyes AO, et al. Adult prostate sarcoma: The MD Anderson Cancer Centre Experience. J Urol 2001;166:521-525.

5. Kim JY, Cho YM, Ro JY. Prostatic stromal sarcoma with rhabdoid features. Ann Diagn Pathol 2010;14:453-456.

6. Cheville JC, Dundore PA, Nascimento AG, et al. Leiomyosarcoma of the prostate. Report of 23 cases. Cancer 1995;76:1422-1427.

7. Gaudin PB, Rosai J, Epstein JI. Sarcomas and related proliferative lesions of specialized prostatic stroma: a clinicopathologic study of 22 cases. Am J Surg Pathol 1998;22:148-162.

8. IARC. Tumors of the urinary system and male genital organs. In: Eble JN, Epstein J, Sesterhenn I, Sauter G, Eds. Pathology and genetics; (World Health Organization Classification of tumors). Lyon: IARC Press; 2004. p. 218-249.

9. Zazzara M, Divenuto L, Scarcia M, et al. Leiomyosarcoma of prostate: Case report and literature review. Urol Case Rep 2018;17:4-6.

10. Macpherson RE, Pratap S, Tyrrell H, et al. Retrospective audit of 957 consecutive (18)F-FDG PET-CT scans compared to CT and MRI in 493 patients with different histological subtypes of bone and soft tissue sarcoma. Clin Sarcoma Res 2018;8:9.

11. Rioja J, Rodriguez-Fraile M, Lima-Favaretto $R$, et al. Role of positron emission tomography in urological oncology. BJUI 2010; 106:1578-1593.

12. Dubey A, Sivananthan G, Bradel T, et al. Prostatic leiomyosarcoma: A rare case report with review of literature. The Internet Journal of Oncology 2010;8.

13. Colombo P, Ceresolli GL, Boiocchi L, et al. Prostatic stromal tumor with fatal outcome in a young man: Histopathological and immunohistochemical case presentation. Rare Tumors 2010;2:4. 